\title{
Extracellular Micro-RNAs in Health and Disease: Basic Science, Biogenesis and Release
}

\author{
Wael Nassar ${ }^{1,2}$, Mervat El-Ansary ${ }^{3}$, Tarek Fayyad4, Mostafa Abdel Aziz ${ }^{2}$ \\ ${ }^{1}$ Department of Nephrology, Sahel Teaching Hospital, General Organization of Teaching Hospitals and \\ Institutes (GOTHI), Cairo, Egypt \\ ${ }^{2}$ Department of Nephrology, Kidney Transplantation Unit, October Six University Hospitals, Cairo, Egypt \\ ${ }^{3}$ Department of Clinical Pathology, Stem Cells Unit, Faculty of Medicine, Cairo University, Cairo, Egypt \\ ${ }^{4}$ Department of Nephrology, Faculty of Medicine, Cairo University, Cairo, Egypt \\ Email: Hegaz_wn@yahoo.com
}

Received 22 September 2015; accepted 2 January 2016; published 5 January 2016

Copyright @ 2016 by authors and Scientific Research Publishing Inc.

This work is licensed under the Creative Commons Attribution International License (CC BY).

http://creativecommons.org/licenses/by/4.0/

CC) (i) Open Access

\begin{abstract}
Small non-protein coding micro-RNAs are regularly exported out of cells, both in health and disease. More than ninety percent of extracellular miRNAs are associated with lower-molecular-mass complexes bound to Argonaute 2 (Ago2), nucleophosmin-1 (NPM1) and high density lipoproteins (HDL), whereas the rest $(\sim 10 \%)$ are membrane-vesicle-encapsulated within exosomes, shedding microvesicles and apoptotic bodies. Regardless of the debate of the nature of circulating miRNA as byproducts of routine cell activities or mediators of cell-cell communication, proper understanding of the molecular behaviors of miRNA in health and disease, is expected to open a new gate for the discovery of new diagnostic tools and possibly therapeutic implementation in the near future.
\end{abstract}

\section{Keywords}

Extracellular miRNAs, Extracellular Vesicles (EVs), Exosomes, Horizontal Gene Transfer (HGT), Microvesicles (MVs)

\section{Introduction}

Since Victor Ambros and Garry Ruvkun discovered micro-RNA (miRNAs), they revolutionized our understanding of the molecular mechanisms of cell function [1]. Functional studies indicate that miRNAs participate in the regulation of almost every cellular process, and are intrinsically associated with much of human pathology

How to cite this paper: Nassar, W., El-Ansary, M., Fayyad, T. and Aziz, M.A. (2016) Extracellular Micro-RNAs in Health and Disease: Basic Science, Biogenesis and Release. American Journal of Molecular Biology, 6, 1-11.

http://dx.doi.org/10.4236/ajmb.2016.61001 
[2]. MiRNAs are endogenously produced, short non-coded RNAs of 21 - 25 nucleotides that are post-transcriptional component of gene regulatory network that modulate the precise amounts of proteins expressed in all cell, frequently by mRNA translation repression or less often by mRNA cleavage or degradation [2] [3].

Recently, it was also shown that mRNA may up-regulate the expression of their target genes as well [4] [5]. It is well documented that a single miRNA can influence hundreds of mRNA gene transcripts and thereby, it has been implicated as a key player in virtually all cell processes [5]-[8]. While the majority of miRNAs are found intra-cellular, a virtual number have been detected outside cells, including various body fluids (i.e. saliva, urine, breast milk, seminal plasma, tears, amniotic fluid, colostrum, bronchial lavage, cerebrospinal fluid, peritoneal fluid, and pleural fluid) from normal individuals [9].

Cells have protective enzymatic and non-enzymatic mechanisms against oxidative stress [10] targeting reconstitution of normal cell function. However, oxidative stress occurs when the reactive oxygen species (ROS) level overwhelms defensive mechanisms [11] [12]. The produced miRNAs under these different conditions varies accordingly. Furthermore, alterations in the level and composition of these extracellular miRNAs, as part of extracellular RNAs (exRNAs), have been well correlated with disease or injurious conditions [13]-[16], suggesting that these extracellular miRNAs can be served as diagnostic and prognostic biomarkers. The source of exRNAs can be endogenous or exogenous, including microbes and foods [17]. Recent findings show that exRNA can act as a signaling molecule, communicating with other cells and carrying genetic information from cell to cell throughout the body [1]. Circulating miRNAs are remarkably stable despite high extracellular RNase activity [9]. In addition to packing within extracellular vesicles (EVs) which are impermeable to RNases, extracellular miRNAs are also packaged in some manner to protect them against RNase digestion, through the formation of protein-miRNA complexes [18].

It is of note here to mention that horizontal gene transfer (HGT) is occurring without genomic integration. Although the study of miRNA is still in the very early stages, current research is exploring the association between various diseases and changes in the type and amount of miRNAs. These diseases include several types of cancer, neurological disorders, heart disease, kidney disease, and more [19]-[22]. This review provides an overview of the properties of extracellular miRNAs, summarizing the current theories regarding extracellular miRNA origin and function, arguing for more compelling translation of circulating miRNAs into clinical practice.

\section{Biogenesis of miRNAs (Figure 1)}

Non-protein coding RNAs (ncRNAs) have linked this class of nucleic acids with a large panel of biological processes, such as homeostasis, development and carcinogenesis [23]-[25]. Different classes of small RNAs continue to be discovered. There are three major classes of animal ncRNAs; microRNAs (miRNAs), short interfering RNAs (siRNAs), and Piwi-interacting RNAs (piRNAs). MiRNAs are small, non-coding RNAs commonly found intra-cellular in all tissues and function as post-transcriptional component of gene regulators. MiRNAs can be generated in a cell by either canonical pathway or non-canonical pathways [26]-[28]. The canonical pathway is Drosha (an RNase III-like protein)/DGCR8 (DiGeorge syndrome critical region gene 8) and Dicer dependent, while the non-canonical pathway may be independent of Drosha/DGCR8 or Dicer. In both pathways, miRNAs are produced via processing and editing, resulting in the formation of mature, functional miRNAs of 21 - 25 nucleotides. Canonical pathway of miRNA biogenesis is responsible for the production of the majority of the known miRNAs. In the canonical pathway, genes are usually transcribed by RNA polymerase II (Pol II) [29] [30]. Arising from intergenic or intragenic (both exonic and intronic) genomic regions. Of note, while endogenous siRNAs originate from double-stranded (ds) RNA precursors, miRNAs and piRNAs are transcribed as long single-stranded (ss) RNAs. Primary transcripts (pri-miR), fold back to form double stranded hairpin structures which are then subjected to sequential processing; first the precursor molecules (pre-miR), 80 - 120 nucleotides long, are produced in the nucleus by type III endonuclease microprocessor DROSHA and its cofactor DGCRA8, followed by their export to the cytoplasm mediated by EXPORTIN 5.

In the cytoplasm, where they are processed by another type III endonuclease, DICER, into the short "active" molecules (guide strand), while the opposite (passenger) strand is preferentially destroyed [31] [32]. MiRNAs are finally loaded onto a multi-protein complex, called RNA-induced silencing complex (RISC), which includes argonaute (Ago) proteins (in humans four Ago proteins are recognized, Ago 1 - 4), have overlapping roles in RISC formation that mediates mRNA degradation or translational repression.

In recent years, several alternative pathways of miRNA biogenesis are identified [31] [32]. Pre-miRNA mimics, endogenous short hairpin RNA (shRNA), other hairpinstructure or other non-coding RNA, can enter the 


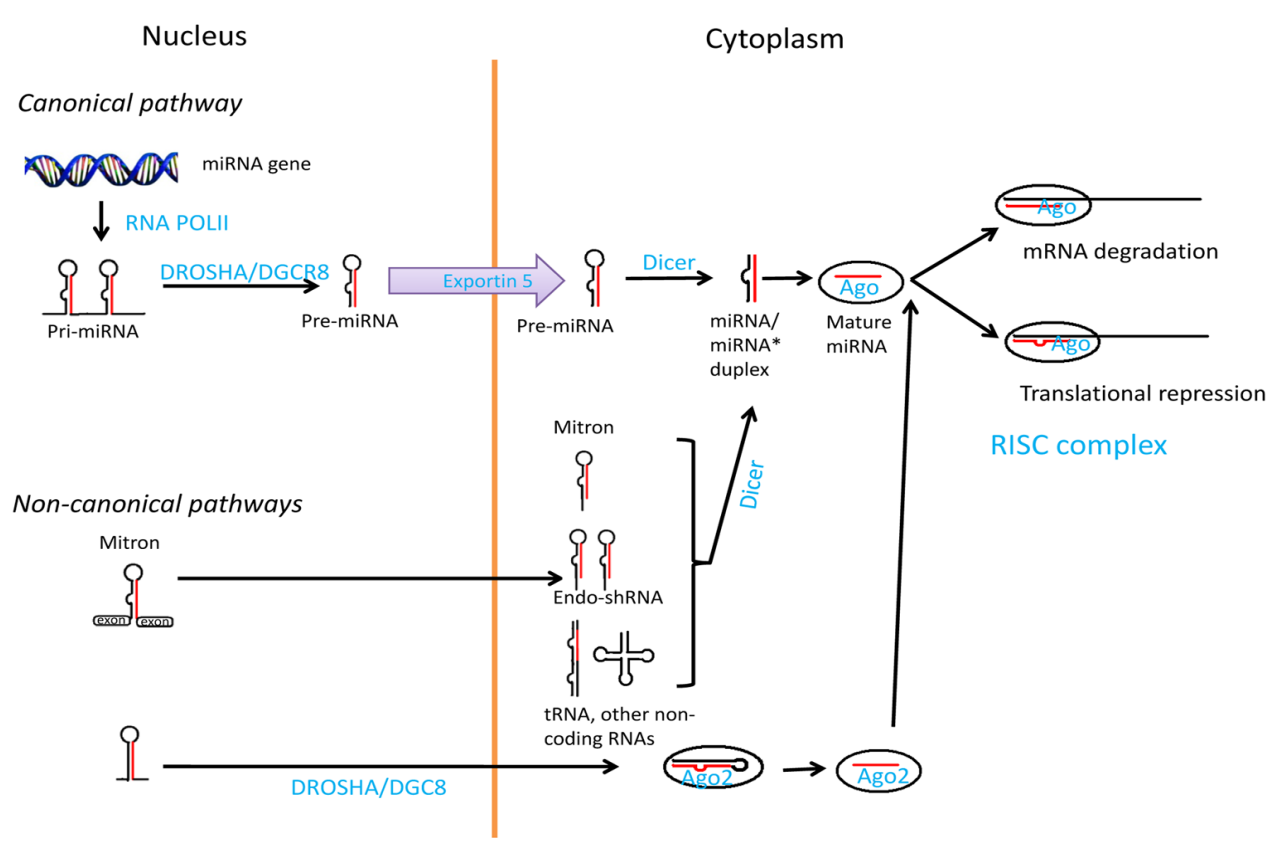

Figure 1. Biogenesis and function of microRNA (miRNA). The majority of miRNA are synthesized through the canonical pathway, in which miRNA genes are transcribed via RNA polymerase II to produce pri-miRNA (long transcripts with multiple hairpin loop structures). Pri-miRNAs are processed by the Microprocessor protein complex containing Drosha/DGCR8, resulting in generation of smaller precursor molecules called pre-miRNAs. After exported from the nucleus via Exportin-5, the pre-miRNAs are further processed via Dicer in the cytoplasm to generate short, doublestranded miRNAs. The mature miRNA direct RISC (a complex containing ago) to target gene mRNA, resulting in mRNA degradation (miRNA/mRNA with perfect complimentary sequences match in RNA). In the non-canonical pathways, miRNAs can be synthesized in either Drosha/DGCR8 or Dicer independent pathways. The short pre-miRNA like precursor can come from mitron, endoshRNA or other noncoding RNA. In some special conditions, the precursor can be processed by Ago2 instead of Dicer to be the mature miRNA (Adopted from Qingquing Wei et al., 2013 [67]).

miRNA biogenesis pathway after direct processing with or without Dicer (non-canonical pathway). The mechanism(s) of piRNA biogenesis remain elusive, and are only found in animals, and specifically in the germline [31] [32].

Argonaute protein uptake of mature miRNA is thought to stabilize the guide strand, while the passenger strand is preferentially destroyed. Argonaute may preferentially retain miRNAs with many targets over miRNAs with few or no targets, leading to degradation of the non-targeting molecules. This turnover of mature miRNA is needed for rapid changes in miRNA expression profiles [33]. MiRNA biogenesis is critically regulated at the levels of epigenetic modulation, gene transcription and miRNA processing.

Many of the miRNA genes are flanked by promoter regions which are governed by specific transcription factors like Myc, p53, and hypoxia-inducible factor (HIF-1) [26]. These observations suggest that pathological challenges are pivotal in regulation of gene expression of miRNAs. In addition, global miRNA expression can also be modulated by the change of proteins or enzymes involved in miRNA processing, e.g. Drosha, exportin-5, Dicer and Ago [34].

\section{Circulating microRNAs}

Circulating extracellular miRNAs are remarkably stable despite high extracellular RNase activity [35]. The membranes of EVs are impermeable to RNases, therefore, attributable to the remarkable stability of vesicle encapsulated miRNA. In addition to packing within EVs, extracellular miRNAs are also packaged in some manner to protect them against RNase digestion, through the formation of protein-miRNA complexes [20] [22] [24] [25] [36] [41].

Both forms, vesicles encapsulated or protein associated, consistently revealed the presence of miRNA in almost all body fluids. Three different possibilities have been suggested to explain the different mechanisms of 
miRNA secretion; i) Passive leakage from injured cells or degraded cells of short half-lives, such as platelets, ii) active secretion via Extracellular vesicles (EVs) and iii) associated with lower-molecular-mass complexes [37]-[42]. Secreted miRNAs are also shown to be remarkably stable despite the austere conditions they are subjected to in both the blood stream (RNase digestion) and during handling (e.g. extreme temperatures and $\mathrm{pH}$ values) [43]-[48]. It has been demonstrated that EVs-associated miRNAs represent the minority, whereas about 90\% of plasma circulating miRNAs are travelling in an AGO-protein-bound form [19] [45]. Similarly, about 99\% of miRNAs exported by cells in culture under normal conditions were membrane-vesicle-free and associated with AGO proteins [45]. It is feasible that the differences in isolation protocols for RNAs could account for the discrepancy in the reported distribution of extracellular miRNA between EVs and protein-bound fraction of serum.

\subsection{Extracellular Vesicle-Encapsulated miRNA}

A major breakthrough was the demonstration that the cargo of EVs included both mRNA and miRNA could be translated into proteins by target cells [47] [48]. Recently, analysis of RNA from EVs demonstrated that EVs contain a large variety of other small noncoding RNA species, including RNA transcripts overlapping with protein-coding regions, repeat sequences, structural RNAs, tRNA fragments, piwi RNA (piRNAs) and small interfering RNAs (siRNAs) [49] [50]. Exosomes are secretory products of endosomal origin, while, microvesicles directly bud from the plasma cell membrane [51]. The mechanism of formation of exosomes is the process of the endosomal pathway, including endocytic vesicles, early endosomes, late endosomes; also known as multivesicular bodies (MVBs) and finally lysosomes [52]. The pathway of multivesicular endosomes (MVEs) that are prone to fuse with lysosomes and predestined for lysosomal degradation, differ from the pathway of secretory MVEs predestined to become secreted as exosomes; i.e. ESCRT-dependent and ESCRT-non-dependent pathways. Endosomal sorting complex responsible for transport (ESCRT) is a four multi-protein complexes assembled within the MVEs: (ESCRT)-0, -I, -II, and -III, with associate accessory proteins (e.g., Alix and VPS4). The ESCRT-0, -I, and -II complexes recognize and sequester ubiquitinated membrane proteins at the endosomal membrane, while the ESCRT-III complex is responsible for membrane budding and actual scission of intraluminal vesicles) ILVs and exosomal release [53]-[55]. An alternative pathway, independent of the ESCRT machinery has also been described, and it includes the ceramide and sphingolipid pathway, in which the enzyme natural sphingomyelinase-2 (nSMase2) is involved inmediation of exosomal release [56] [57]. Exosomes are released by a wide spectrum of cell types and their release appears to be modulated by micro-environmental milieu and influenced by growth factors, heat shock and stress conditions, $\mathrm{pH}$ variations and therapy [58]-[60]. The mechanisms by which EVs affect the target cells include transfer/activation of signaling protein receptors or intercellular exchange of proteins and RNAs, which are both recruited to induce phenotypic modulation in the target cells [61].

\subsection{Protein-Associated miRNA}

Recently, accumulated data suggest that the majority of circulating miRNAs may not be only confined within extracellular vesicles, but a substantial fraction is also bound to protein complexes, such as high density lipoproteins (HDL), Argonaute-2 (Ago2) and nucleophosmin-1 (NPM-1). HDL bounded miRNA has been reported to be present in the plasma of healthy subjects. The uptake of HDL bounded miRNA seems to be dependent on the interplay between cholesteryl ester of HDL and the cell surface HDL receptor, named scavenger receptor class B, type I (SR-BI) [44].

Turchinovich and colleagues [43], showed that the majority of miRNAs found in human plasma, are associated with Ago2 and that the high proportion of Ago-miRNA may represent by-products of dead cells, since Ago-miRNA complexes, which are known to be present within Exosomes, are known to be extremely stable within cells [59], and it may be derived from vesicles potentially damaged during purification [74].

These findings raise indeed intriguing questions about whether these miRNAs have a different biological role and source; researchers have proposed that miRNA-protein complexes may be released into circulation as a consequence of cell lysis or necrosis, meaning that if participated in cell-cell communication this might incidentally occur under certain circumstances including cell stress and intra-cytoplasmic accumulation of unfolded or misfolded proteins. Nonetheless, it is believed that the role of these complexes has not been discovered yet. 


\section{MiRNA Release: Active Sorting or Byproduct of Cell Activity!}

Two hypothesizes have been postulated to explain the presence of circulating extracellular miRNA, both, vesicles encapsulated or protein associated. MiRNA release either by the selective sorting system or mere byproduct of cell activity and waste disposal is yet debatable. Accumulating evidence, however, suggests that both theories can be true [43]. The hypothesis of cell activity byproduct has been claimed by the some observations; miRNA remains stable for weeks in cell lysate without enzymatic inhibition (e.g. RNases), which support the notion of simple passive release of miRNA in response to over production and cytoplasmic crowd [42]. Moreover, miRNA produced by several cell lines after three days culture under normal conditions was significantly lower than their parental cells of origin which supports this notion. Besides, the extracellular miRNA production by some cell lines is mainly (>95\%) in a protein-associated state [42]. Moreover, apart from crowd and overflow release, yet, no clear indication of either active release of vesicle-free AGO2-miRNA complexes from cells or their uptake by recipient cells in mammals [43]. In contrast, miRNAs entrapped within microvesicles can horizontally transfer gene information to recipient cells, modulate gene expression and trigger functional effects [62] [63]. The exact mechanisms by which cells scission/release EVs containing miRNAs remains incompletely understood; however, the release is multifactorial and modulated particularly by extracellular signals [64]. Microvesicles are released by direct budding from the plasma cell membrane, whereas exosomes release process might be ceramide enzyme nSMase2-dependent or nondependent machinery [65]. However, exosome release is blocked by inhibiting nSMase2 (neutral sphingomyelinase 2) and interestingly, inhibition of nSMase2 actually increases the export of miRNAs by HDL [65], suggesting two different pathways to exert the same action, meaning, two distinct mechanisms and/or competition in the export pathways. Moreover, the ESCRT-III complex is responsible for membrane budding and actual scission of intraluminal vesicles (ILVs) and exosomal release [53]-[55]. The activation of nSMase2 enzyme and ESCRT-III complex and their involvement in the release of vesicles might be a response to the crowd and overflow proposition. This means that, in case of crowd and overflow, the cell endosomal pathway is unable to cope with the abrupt increase in the need for degradation through the endocytic pathway, hence activation of an alternative pathway to eliminate and secrete these contents outside the cell. Other observations have been supporting the hypothesis of active sorting; high EVs miRNA level than that contained in the parental cells which may be explained by the observation that certain miRNAs can be lost during extraction from samples [66]. The differences in the blood collection protocols willimpact the comparison between extracellular versus intracellular miRNA profiles expressed in different cell types [67]-[71].

\section{Function of miRNA}

Each class of small RNAs binds to a member of the Argonaute (Ago) family of proteins. The Argonaute protein family includes eight members (Ago 1 - 4, present in all mammalian cells and Piwi 1 - 4, found in the germ line and hematopoietic stem cells) in the human genome [68]. The siRNAs and miRNAs associate the Ago clade, whereas piRNAs associate the Piwi clade [69]. The Ago protein bound to the small RNA comprises the RNAinduced silencing complex (RISC). The RISCs containing miRNAs are primarily target messenger RNAs (mRNAs) by either complete complementarity causing degradation of the mRNAs or incomplete complementarity, causing translation repression (slowing or preventing mRNA translation) [70], a combination of the two is hotly debated. However, the balance between repressed and degraded mRNA might play an integral role as post-transcriptional component of gene regulatory network that modulate the precise amounts and type of proteins expressed in cells. MiRNA is a crucial player in gene regulation through different mechanisms of actions mostly controlling gene transcription and translation processes [69]. Recently, miRNA has been also reported to induce histone modifications methylation of the DNA promotor sites and thus, ameliorating the target gene expression [70].

\section{Clinical Applications of Extracellular miRNA}

The search for novel, early disease predictors represent a current and a permanent challenge in disease recognition. MiRNAs offer a new class of biologically active molecules that contribute many disease processes [71]. Accumulating evidences showed that circulating extracellular miRNA, both, vesicles encapsulated or protein-associated can serve as disease biomarkers [72]. Some points need to be cleared to maximize the benefit 
and minimize the pitfalls. Cell contribution in the disease state within the same organ varies among different cells of the same organ. This variability may be attributed to the stress phase, which differs among cells even within the same organ. RNA microarray profiling of intracellular miRNA may only reflect the stress phase of a particular cell. On the other hand, extracellular circulating miRNA represents the final net result of miRNAs that produced by most of involved cells. Besides, vesicles are subjected to shearing force associated with centrifugation and filtration that might alter its miRNA contents [72]. But the possibility of other distant organ miRNA release that might alter the interpretation of the results is still there. Confounding biological and technical factors, such as age or gender of patients as well as storage conditions and processing protocols, are essential in order to judge the value of miRNAs as biomarkers [72]. Besides, identification of a set of extracellular miRNAs rather than single up or down regulated miRNA against intracellular protein microarray would be more reliable biomarker for a specific disease. Recently, not only miRNA are recognized as disease biomarkers, but also miRNAs signatures are increasingly recognized as valuable biomarkers for a differential diagnosis in clinically overlapping diseases such as non-ischemic systolic heart failure versus acute myocardial infarction [73].

Nishimura N. and his collaborators addressed the combination of miRNA and siRNA in nanoliposomal particles to target oncogenic pathways altered in ovarian cancer. Combined targeting of the Eph pathway using EphA2 -targeting siRNA and the tumor suppressor miR-520d-3p exhibits remarkable therapeutic synergy and enhanced tumor suppression in vitro and in vivo compared with either monotherapy alone [74].

Recently, miR-423-5p, miR-18b-3p, miR-129-5p, miR-1254, miR-675, and miR-622) were reported to be elevated in patients with heart failure, with miR-423-5p positively correlated with N-terminal pro-brain natriuretic peptide (NT-proBNP) levels and most strongly related to the clinical diagnosis of heart failure [75]. Besides, plasma levels of miR-208b and miR-499 both have been highly associated with AMI. Also, it was demonstrated that measuring miR-1 in plasma is a good approach for blood-based detection of human AMI [76]. Circulating miR-1 is significantly increased in the blood of AMI patients compared to non-AMI subjects and were positively correlated with serum CK-MB (Creatine kinase-MB) [77].

Kato and collaborators recently show that miR-192 levels increase significantly in glomeruli isolated from streptozotocin-injected diabetic mice as well as diabetic $\mathrm{db} / \mathrm{db}$ mice, in parallel with increased TGF- $\beta 1$ and collagen 1a2 (Col1a2) levels [78]. Upregulation of renal miR-192 during diabetic kidney diseases is also found in $\mathrm{db} / \mathrm{db}$ mice, type 2 diabetes rat, and whole blood samples of type 2 diabetes patients [79].

\section{Conclusions}

The fact that diverse diseases in different organ systems (liver, kidney, pancreas, heart, lung and skin) may end with fibrotic changes suggests common pathogenic pathways. These pathways are orchestrated by complex activities within different cells in which specific molecular pathways and gene expression have emerged. These specific molecules are cell specific (relates to the stress phase of cells involved), rather than organ specific. Current researches are exploring the association between various diseases and changes in miRNAs as part of molecular pathways activation. The activation of molecular pathways of cell stress in different diseases seems to be more or less similar regardless the organ involved in a specific disease; resulting in cellular dysfunction, parenchymal scarring and ultimately organ failure. The clinical presentation of any disease can be explained as "functional expression of cell disruption" depending on the cell mass involved in this response.

As all living organisms should have a facility to get rid of their metabolic wastes. Exosomes, microvesicles, apoptotic bodies and protein associated nucleoproteins might be some forms of cell excreta. Two hypothesizes have been postulated to explain the presence of circulating extracellular RNAs, both, vesicles encapsulated or protein associated. RNAs release either by the selective sorting system or mere byproduct of cell activity and waste disposal is yet debatable. Accumulating evidence, however, suggests that both theories can be true. Extracellular nucleoproteins consist of a variety of factors among which miRNA is seemingly of particular importance in response to molecular pathways activation. Yet, we treat most of diseases after the onset of the functional disturbances, while thorough understanding of the molecular cell biology will enable us to diagnose and hence treat cells far before the onset of symptoms and signs by targeting molecular cell disruption in which miRNA is a pivotal player.

The response of cells to stress, which can be physical, chemical or biological stressor(s), is a series of biological events that facilitate and promote counteraction and adaptation to qualify these cells to survive. Cell adaptation can be categorized into five major types including atrophy, hypertrophy, hyperplasia, dysplasia and metap- 
lasia. The adaptation may be physiologic or pathologic. In case of failure of adaptation, cells will proceed to a state of cell death, through undergoing autophagy, apoptosis and necrosis. From cell adaptation to cell death, the process of fibro-genesis is activated to modulate the final anatomical and physiological outcome of the tissue in reaction to stress. Duration, severity and frequency of exposure to stressors are detrimental for the nature of cell response to stress. Correlation between exRNA profiles in various adaptation mechanisms has not yet been thoroughly investigated. This profile will expedite the discovery of complex panel of biomarkers to monitor specific disease states along the complete pathogenic pathway for prediction, initiation, development, diagnosis, progression, regression, and treatment efficacy of the disease.

\section{Acknowledgements}

The authors gratefully acknowledge Rashad S. Barsoum, Professor of Internal Medicine and Nephrology, Faculty of Medicine, Cairo University, Egypt, for his unlimited help and support. We wish also to acknowledge Dr. Mayar W.N., Faculty of Medicine; October Six University, whose efforts were behind most of the steps of this work.

\section{Conflict of Interest}

We, the authors of this review, declare that there is no conflict of interest that could be perceived as prejudicing impartiality of the research. We fully declare that no financial or other potential conflict of interest.

\section{References}

[1] Lee, R.C., Feinbaum, R.L. and Ambros, V. (1993) The C. elegans Heterochronic Gene Lin-4 Encodes Small RNAs with Antisense Complementarity to Lin-14. Cell, 75, 843-854. http://dx.doi.org/10.1016/0092-8674(93)90529-Y

[2] Hou, J.H. and Zhao, D. (2013) MicroRNA Regulation in Renal Pathophysiology. International Journal of Molecular Sciences, 14, 13078-13092. http://dx.doi.org/10.3390/ijms140713078

[3] He, L. and Hannon, G.J. (2004) MicroRNAs: Small RNAs with a Big Role in Gene Regulation. Nature Reviews Genetics, 5, 522-531. http://dx.doi.org/10.1038/nrg1379

[4] Filipowicz, W., Bhattacharyya, S.N. and Sonenberg, N. (2008) Mechanisms of Post-Transcriptional Regulation by Micrornas: Are the Answers in Sight? Nature Reviews Genetics, 9, 102-114. http://dx.doi.org/10.1038/nrg2290

[5] Eulalio, A., Huntzinger, E. and Izaurralde, E. (2008) Getting to the Root of miRNA-Mediated Gene Silencing. Cell, 132, 9-14. http://dx.doi.org/10.1016/j.cell.2007.12.024

[6] Baek, D., Villén, J., Shin, C., Camargo, F.D., Gygi, S.P. and Bartel, D.P. (2008) The Impact of microRNAs on Protein Output. Nature, 455, 64-71. http://dx.doi.org/10.1038/nature07242

[7] Selbach, M., Schwanhäusser, B., Thierfelder, N., Fang, Z., Khanin, R. and Rajewsky, N. (2008) Widespread Changes in Protein Synthesis Induced by microRNAs. Nature, 455, 58-63. http://dx.doi.org/10.1038/nature07228

[8] van Rooij, E. and Olson, E.N. (2007) MicroRNAs: Powerful New Regulators of Heart Disease and Provocative Therapeutic Targets. Journal of Clinical Investigation, 117, 2369-2376. http://dx.doi.org/10.1172/JCI33099

[9] Mitchell, P.S., Parkin, R.K., Kroh, E.M., Fritz, B.R., Wyman, S.K., Pogosova-Agadjanyan, E.L., Peterson, A., Noteboom, J., O’Briant, K.C., Allen, A., Lin, D.W., Urban, N., Drescher, C.W., Knudsen, B.S., Stirewalt, D.L., Gentleman, R., Vessella, R.L., Nelson, P.S., Martin, D.B. and Tewari, M. (2008) Circulating microRNAs as Stable Blood-Based Markers for Cancer Detection. Proceedings of the National Academy of Sciences of the USA, 105, 10513-10518. http://dx.doi.org/10.1073/pnas.0804549105

[10] Genestra, M. (2007) Oxyl Radicals, Redox-Sensitive Signalling Cascades and Antioxidants. Cellular Signalling, 19, 1807-1819. http://dx.doi.org/10.1016/j.cellsig.2007.04.009

[11] Sies, H. (1985) Introductory Remarks. In: Sies, H., Ed., Oxidative Stress, Academic Press, London, 1-8. http://dx.doi.org/10.1016/B978-0-12-642760-8.50005-3

[12] Sies, H. (1997) Oxidative Stress: Oxidants and Antioxidants. Experimental Physiology, 82, 291-295. http://dx.doi.org/10.1113/expphysiol.1997.sp004024

[13] Laterza, O.F., Lim, L., Garrett-Engele, P.W., Vlasakova, K., Muniappa, N., Tanaka, W.K., Johnson, J.M., Sina, J.F., Fare, T.L., Sistare, F.D. and Glaab, W.E. (2009) Plasma MicroRNAs as Sensitive and Specific Biomarkers of Tissue Injury. Clinical Chemistry, 55, 1977-1983. http://dx.doi.org/10.1373/clinchem.2009.131797

[14] Wang, K., Zhang, S., Marzolf, B., Troisch, P., Brightman, A., Hu, Z., Hood, L.E. and Galas, D.J. (2009) Circulating microRNAs, Potential Biomarkers for Drug-Induced Liver Injury. Proceedings of the National Academy of Sciences of 
the United States of America, 106, 4402-4407. http://dx.doi.org/10.1073/pnas.0813371106

[15] Kosaka, N., Iguchi, H. and Ochiya, T. (2010) Circulating microRNA in Body Fluid: A New Potential Biomarker for Cancer Diagnosis and Prognosis. Cancer Science, 101, 2087-2092. http://dx.doi.org/10.1111/j.1349-7006.2010.01650.x

[16] Dimmeler, S. and Zeiher, A.M. (2010) Circulating microRNAs: Novel Biomarkers for Cardiovascular Diseases? European Heart Journal, 31, 2705-2707. http://dx.doi.org/10.1093/eurheartj/ehq221

[17] Fichtlscherer, S., De Rosa, S., Fox, H., Schwietz, T., Fischer, A., Liebetrau, C., Weber, M., Hamm, C.W., Röxe, T., Müller-Ardogan, M., Bonauer, A., Zeiher, A.M. and Dimmeler, S. (2010) Circulating microRNAs in Patients with Coronary Artery Disease. Circulation Research, 107, 677-684. http://dx.doi.org/10.1161/CIRCRESAHA.109.215566

[18] Wang, K., Zhang, S., Weber, J., Baxter, D. and Galas, D.J. (2010) Export of microRNAs and microRNA-Protective Protein by Mammalian Cells. Nucleic Acids Research, 38, 7248-7259. http://dx.doi.org/10.1093/nar/gkq601

[19] Zernecke, A., Bidzhekov, K., Noels, H., Shagdarsuren, E., Gan, L., Denecke, B., Hristov, M., Köppel, T., Jahantigh, M.N., Lutgens, E., Wang, S., Olson, E.N., Schober, A. and Weber, C. (2009) Delivery of microRNA-126 by Apoptotic Bodies Induces CXCL12-Dependent Vascular Protection. Science Signaling, 2, ra81. http://dx.doi.org/10.1126/scisignal.2000610

[20] Eldh, M., Ekström, K., Valadi, H., Sjöstrand, M., Olsson, B., Jernås, M. and Lötvall, J. (2010) Exosomes Communicate Protective Messages during Oxidative Stress; Possible Role of Exosomal Shuttle RNA. PLoS ONE, 5, e15353. http://dx.doi.org/10.1371/journal.pone.0015353

[21] Yuan, A., Farber, E.L., Rapoport, A.L., Tejada, D., Deniskin, R., Akhmedov, N.B. and Farber, D.B. (2009) Transfer of microRNAs by Embryonic Stem Cell Microvesicles. PLoS ONE, 4, e4722. http://dx.doi.org/10.1371/journal.pone.0004722

[22] Akao, Y., Iio, A., Itoh, T., Noguchi, S., Itoh, Y., Ohtsuki, Y. and Naoe, T. (2011) Microvesicle-Mediated RNA Molecule Delivery System Using Monocytes/Macrophages. Molecular Therapy, 19, 395-399. http://dx.doi.org/10.1038/mt.2010.254

[23] Turchinovich, A., Weiz, L., Langheinz, A. and Burwinkel, B. (2011) Characterization of Extracellular Circulating microRNA. Nucleic Acids Research, 39, 7223-7233.

[24] Arroyo, J.D., Chevillet, J.R., Kroh, E.M., Ruf, I.K., Pritchard, C.C., Gibson, D.F., Mitchell, P.S., Bennett, C.F., Pogosova-Agadjanyan, E.L., Stirewalt, D.L., Tait, J.F. and Tewari, M. (2011) Argonaute2 Complexes Carry a Population of Circulating microRNAs Independent of Vesicles in Human Plasma. Proceedings of the National Academy of Sciences of the United States of America, 108, 5003-5008.

[25] Vickers, K.C., Palmisano, B.T., Shoucri, B.M., Shamburek, R.D. and Remaley, A.T. (2011) MicroRNAs Are Transported in Plasma and Delivered to Recipient Cells by High-Density Lipoproteins. Nature Cell Biology, 13, 423-433. http://dx.doi.org/10.1038/ncb2210

[26] Bhatt, K., Mi, Q.S. and Dong, Z. (2011) MicroRNAs in Kidneys: Biogenesis, Regulation, and Pathophysiological Roles. American Journal of Physiology—Renal Physiology, 300, F602-F610. http://dx.doi.org/10.1152/ajprenal.00727.2010

[27] Miyoshi, K., Miyoshi, T. and Siomi, H. (2010) Many Ways to Generate microRNA-Like Small RNAs: Noncanonical Pathways for microRNA Production. Molecular Genetics and Genomics, 284, 95-103. http://dx.doi.org/10.1007/s00438-010-0556-1

[28] Yang, J.S. and Lai, E.C. (2011) Alternative miRNA Biogenesis Pathways and the Interpretation of Core miRNA Pathway Mutants. Molecular Cell, 43, 892-903. http://dx.doi.org/10.1016/j.molcel.2011.07.024

[29] Lee, Y., Kim, M., Han, J., Yeom, K.H., Lee, S., Baek, S.H. and Kim, V.N. (2004) MicroRNA Genes Are Transcribed by RNA Polymerase II. EMBO Journal, 23, 4051-4060. http://dx.doi.org/10.1038/sj.emboj.7600385

[30] Faller, M. and Guo, F. (2008) MicroRNA Biogenesis: There’s More Than One Way to Skin a Cat. Biochimica et Biophysica Acta, 1779, 663-667. http://dx.doi.org/10.1016/j.bbagrm.2008.08.005

[31] Malone, C.D. and Hannon, G.J. (2009) Small RNAs as Guardians of the Genome. Cell, 136, 656-668. http://dx.doi.org/10.1016/j.cell.2009.01.045

[32] Hagiwara, K., Ochiya, T. and Kosaka, N. (2014) A Paradigm Shift for Extracellular Vesicles as Small RNA Carriers: From Cellular Waste Elimination to Therapeutic Applications. Drug Delivery and Translational Research, 4, 31-37. http://dx.doi.org/10.1007/s13346-013-0180-9

[33] Kai, Z.S. and Pasquinelli, A.E. (2010) MicroRNA Assassins: Factors That Regulate the Disappearance of miRNAs. Nature Structural \& Molecular Biology, 17, 5-10. http://dx.doi.org/10.1038/nsmb.1762

[34] Siomi, H. and Siomi, M.C. (2010) Posttranscriptional Regulation of microRNA Biogenesis in Animals. Molecular Cell, 38, 323-332. http://dx.doi.org/10.1016/j.molcel.2010.03.013 
[35] Mitchell, P.S., Parkin, R.K., Kroh, E.M., Fritz, B.R., Wyman, S.K., Pogosova-Agadjanyan, E.L., Peterson, A., Noteboom, J., O’Briant, K.C., Allen, A., Lin, D.W., Urban, N., Drescher, C.W., Knudsen, B.S., Stirewalt, D.L., Gentleman, R., Vessella, R.L., Nelson, P.S., Martin, D.B. and Tewari, M. (2008) Circulating microRNAs as Stable Blood-Based Markers for Cancer Detection. Proceedings of the National Academy of Sciences of the United States of America, 105, 10513-10518. http://dx.doi.org/10.1073/pnas.0804549105

[36] Hanke, M., Hoefig, K., Merz, H., et al. (2010) A Robust Methodology to Study Urine microRNA as Tumor Marker: microRNA-126 and microRNA-182 Are Related to Urinary Bladder Cancer. Urologic Oncology, 28, 655-661. http://dx.doi.org/10.1016/j.urolonc.2009.01.027

[37] Park, N.J., Zhou, H., Elashoff, D., et al. (2009) Salivary microRNA: Discovery, Characterization, and Clinical Utility for Oral Cancer Detection. Clinical Cancer Research, 15, 5473-5477. http://dx.doi.org/10.1158/1078-0432.CCR-09-0736

[38] Weber, J.A., Baxter, D.H., Zhang, S., et al. (2010) The microRNA Spectrum in 12 Body Fluids. Clinical Chemistry, 56, 1733-1741. http://dx.doi.org/10.1373/clinchem.2010.147405

[39] Kosaka, N., Izumi, H., Sekine, K. and Ochiya, T. (2010) MicroRNA as a New Immune-Regulatory Agent in Breast Milk. Silence, 1, 7. http://dx.doi.org/10.1186/1758-907X-1-7

[40] Valadi, H., Ekström, K., Bossios, A., et al. (2007) Exosome-Mediated Transfer of mRNAs and microRNAs Is a Novel Mechanism of Genetic Exchange between Cells. Nature Cell Biology, 9, 654-659. http://dx.doi.org/10.1038/ncb1596

[41] Hunter, M.P., Ismail, N., Zhang, X.L., et al. (2008) Detection of microRNA Expression in Human Peripheral Blood Microvesicles. PLoS ONE, 3, e3694. http://dx.doi.org/10.1371/journal.pone.0003694

[42] Turchinovich, A., Weiz, L., Langheinz, A. and Burwinkel, B. (2011) Characterization of Extracellular Circulating microRNA. Nucleic Acids Research, 39, 7223-7233. http://dx.doi.org/10.1093/nar/gkr254

[43] Turchinovich, A., Weiz, L. and Burwinkel, B. (2012) Extracellular miRNAs: The Mystery of Their Origin and Function. Trends in Biochemical Sciences, 2012, 1-6.

[44] Winter, J., Jung, S., Keller, S., et al. (2009) Many Roads to Maturity: MicroRNA Biogenesis Pathways and Their Regulation. Nature Cell Biology, 11, 228-234. http://dx.doi.org/10.1038/ncb0309-228

[45] Kosaka, N., Iguchi, H., Ochiya, T., et al. (2010) Circulating microRNA in Body Fluid: A New Potential Biomarker for Cancer Diagnosis and Prognosis. Cancer Science, 101, 2087-2092. http://dx.doi.org/10.1111/j.1349-7006.2010.01650.x

[46] Kosaka, N. and Ochiya, T. (2011) Unraveling the Mystery of Cancer by Secretary microRNA: Horizontal microRNA Transfer between Living Cells. Frontiers in Genetics, 2, 97.

[47] Chen, X., Liang, H.W., Zhang, J.F., et al. (2012) Horizontal Transfer of microRNAs: Molecular Mechanisms and Clinical Applications. Protein Cell, 3, 28-37. http://dx.doi.org/10.1007/s13238-012-2003-z

[48] Tompkins, A.J., Chatterjee, D., Maddox, M., Wang, J., Arciero, E., et al. (2015) The Emergence of Extracellular Vesicles in Urology: Fertility, Cancer, Biomarkers and Targeted Pharmacotherapy. Journal of Extracellular Vesicles, 4, 23815. http://dx.doi.org/10.3402/jev.v4.23815

[49] Mittelbrunn, M., Gutiérrez-Vázquez, C., Villarroya-Beltri, C., González, S., Sánchez-Cabo, F., González, M.A., Bernad, A. and Sánchez-Madrid, F. (2011) Unidirectional Transfer of microRNA-Loaded Exosomes from T Cells to Antigen-Presenting Cells. Nature Communications, 2, 282-210. http://dx.doi.org/10.1038/ncomms1285

[50] Montecalvo, A., Larregina, A.T., Shufesky, W.J., Stolz, D.B., Sullivan, M.L., Karlsson, J.M., Baty, C.J., Gibson, G.A., Erdos, G., Wang, Z., et al. (2012) Mechanism of Transfer of Functional microRNAs between Mouse Dendritic Cells via Exosomes. Blood, 119, 756-766. http://dx.doi.org/10.1182/blood-2011-02-338004

[51] Mathivanan, S., Ji, H. and Simpson, R.J. (2010) Exosomes: Extracellular Organelles Important in Intercellular Communication. Journal of Proteomics, 73, 1907-1920. http://dx.doi.org/10.1016/j.jprot.2010.06.006

[52] Valapala, M. and Vishwanatha, J.K. (2011) Lipid Raft Endocytosis and Exosomal Transport Facilitate Extracellular Trafficking of Annexin A2. Journal of Biological Chemistry, 286, 30911-30925. http://dx.doi.org/10.1074/jbc.M111.271155

[53] Raiborg, C. and Stenmark, H. (2009) The ESCRT Machinery in Endosomal Sorting of Ubiquitylated Membrane Proteins. Nature, 458, 445-452. http://dx.doi.org/10.1038/nature07961

[54] Stenmark, H. (2009) Rab GTPases as Coordinators of Vesicle Traffic. Nature Reviews Molecular Cell Biology, 10, 513-525. http://dx.doi.org/10.1038/nrm2728

[55] Hurley, J.H. (2010) The ESCRT Complexes. Critical Reviews in Biochemistry and Molecular Biology, 45, $463-487$. http://dx.doi.org/10.3109/10409238.2010.502516

[56] Marsh, M. and van Meer, G. (2008) Cell Biology. No ESCRTs for Exosomes. Science, 319, 1191-1192. http://dx.doi.org/10.1126/science.1155750 
[57] Trajkovic, K., Hsu, C., Chiantia, S., Rajendran, L., Wenzel, D., Wieland, F., Schwille, P., Brugger, B. and Simons, M. (2008) Ceramide Triggers Budding of Exosome Vesicles into Multivesicular Endosomes. Science, 319, 1244-1247. http://dx.doi.org/10.1126/science.1153124

[58] Hedlund, M., Nagaeva, O., Kargl, D., Baranov, V. and Mincheva-Nilsson, L. (2011) Thermal- and Oxidative Stress Causes Enhanced Release of NKG2D Ligand-Bearing Immunosuppressive Exosomes in Leukemia/Lymphoma $\mathrm{T}$ and B Cells. PLoS ONE, 6, e16899. http://dx.doi.org/10.1371/journal.pone.0016899

[59] Khan, S., Jutzy, J.M., Aspe, J.R., McGregor, D.W., Neidigh, J.W. and Wall, N.R. (2011) Survivin Is Released from Cancer Cells via Exosomes. Apoptosis, 16, 1-12. http://dx.doi.org/10.1007/s10495-010-0534-4

[60] Ciravolo, V., Huber, V., Ghedini, G.C., Venturelli, E., Bianchi, F., Campiglio, M., Morelli, D., Villa, A., Della Mina, P., Menard, S., et al. (2012) Potential Role of HER2-Overexpressing Exosomes in Countering Trastuzumab-Based Therapy. Journal of Cellular Physiology, 227, 658-667. http://dx.doi.org/10.1002/jcp.22773

[61] Corrado, C., Raimondo, S., Chiesi, A., Ciccia, F., DeLeo, G. and Alessandro, R. (2013) Exosomes as Intercellular Signaling Organelles Involved in Health and Disease: Basic Science and Clinical Applications. International Journal of Molecular Sciences, 14, 5338-5366. http://dx.doi.org/10.3390/ijms14035338

[62] Xin, H., Li, Y., Buller, B., et al. (2012) Exosome-Mediated Transfer of miR-133b from Multipotent Mesenchymal Stromal Cells to Neural Cells Contributes to Neurite Outgrowth. Stem Cells, 30, 1556-1564. http://dx.doi.org/10.1002/stem.1129

[63] Hergenreider, E., Heydt, S., Tréguer, K., et al. (2012) Atheroprotective Communication between Endothelial Cells and Smooth Muscle Cells through miRNAs. Nature Cell Biology, 14, 249-256. http://dx.doi.org/10.1038/ncb2441

[64] Kim, Y.K., Yeo, J., Kim, B., et al. (2012) Short Structured RNAs with Low GC Content Are Selectively Lost during Extraction from a Small Number of Cells. Molecular Cell, 46, 893-895. http://dx.doi.org/10.1016/j.molcel.2012.05.036

[65] Raposo, G. and Stoorvogel, W. (2013) Extracellular Vesicles: Exosomes, Microvesicles, and Friends. Journal of Cell Biology, 200, 373-383.

[66] Perez, A., Loizaga, A., Arceo, R., Lacasa, I., Rabade, A., Zorroza, K., et al. (2014) A Pilot Study on the Potential of RNA-Associated to Urinary Vesicles as a Suitable Non-Invasive Source for Diagnostic Purposes in Bladder Cancer. Cancers, 6, 179-192.

[67] Wei, Q.Q., Mi, Q.-S. and Zheng, D. (2013) The Regulation and Function of MicroRNAs in Kidney Diseases. International Union of Biochemistry and Molecular Biology, 65, 602-615. http://dx.doi.org/10.1002/iub.1174

[68] Pratt, A.J. and MacRae, I.J. (2009) The RNA-Induced Silencing Complex: A Versatile Gene-Silencing Machine. Journal of Biological Chemistry, 284, 17897-17901. http://dx.doi.org/10.1074/jbc.R900012200

[69] Li, R., Chung, A.C.K., Yu, X.Q. and Lan, H.Y. (2014) MicroRNAs in Diabetic Kidney Disease. International Journal of Endocrinology, 2014, Article ID: 593956. http://dx.doi.org/10.1155/2014/593956

[70] Djuranovic, S., Nahvi, A., Green, R. (2012) MiRNA-Mediated Gene Silencing by Translational Repression Followed by mRNA Deadenylation and Decay. Science, 336, 237-240. http://dx.doi.org/10.1126/science.1215691

[71] Keller, A., Leidinger, P., Vogel, B., Backes, C., ElSharawy, A., Galata, V., Müller, S.C., Marquart, S., Schrauder, M.G., Strick, R., Bauer, A., Wischhusen, J., Beier, M., Kohlhaas, J., Katus, H.A., Hoheisel, J., Franke, A., Meder, B. and Meese, E. (2014) miRNAs Can Be Generally Associated with Human Pathologies as Exemplified for miR-144. BMC Medicine, 12, 224. http://dx.doi.org/10.1186/s12916-014-0224-0

[72] Taylor, D.D. and Gercel-Taylor, C. (2013) The Origin, Function, and Diagnostic Potential of RNA within Extracellular Vesicles Present in Human Biological Fluids. Frontiers in Genetics, 4, 142.

[73] Meder, B., Backes, C., Haas, J., Leidinger, P., Stahler, C., Grossmann, T., Vogel, B., Frese, K., Giannitsis, E., Katus, H.A., Meese, E. and Keller, A. (2014) Influence of the Confounding Factors Age and Sex on microRNA Profiles from Peripheral Blood. Clinical Chemistry, 60, 1200-1208. http://dx.doi.org/10.1373/clinchem.2014.224238

[74] Nishimura, M., Jung, E.-J., Shah, M.Y., et al. (2013) Therapeutic Synergy between microRNA and siRNA in Ovarian. Cancer Treatment. Cancer Discovery, 3, 1302-1315. http://dx.doi.org/10.1158/2159-8290.CD-13-0159

[75] Kinet, V., Halkein, J., Dirkx, E. and De Windt, L.J. (2013) Cardiovascular Extracellular microRNAs: Emerging Diagnostic Markers and Mechanisms of Cell-to-Cell RNA Communication. Frontiers in Genetics, 4, 1-7.

[76] Ai, J., Zhang, R., Li, Y., Pu, J., Lu, Y., Jiao, J., et al. (2010) Circulating microRNA-1 as a Potential Novel Biomarker for Acute Myocardial Infarction. Biochemical and Biophysical Research Communications, 391, 73-77. http://dx.doi.org/10.1016/j.bbrc.2009.11.005

[77] Cheng, Y., Tan, N., Yang, J., Liu, X., Cao, X., He, P., et al. (2010) A Translational Study of Circulating Cell-Free microRNA-1 in Acute Myocardial Infarction. Clinical Science, 119, 87-95. http://dx.doi.org/10.1042/CS20090645

[78] Kato, M., Zhang, J., Wang, M., et al. (2007) MicroRNA-192 in Diabetic Kidney Glomeruli and Its Function in TGF- $\beta$ Induced Collagen Expression via Inhibition of E-Box Repressors. Proceedings of the National Academy of Sciences of 
the United States of America, 104, 3432-3437. http://dx.doi.org/10.1073/pnas.0611192104

[79] Long, J., Wang, Y., Wang, W., Chang, B.H.J. and Danesh, F.R. (2011) MicroRNA-29c Is a Signature MicroRNA under High Glucose Conditions That Targets Sprouty Homolog 1, and Its in Vivo Knockdown Prevents Progression of Diabetic Nephropathy. The Journal of Biological Chemistry, 286, 11837-11848.

http://dx.doi.org/10.1074/jbc.M110.194969 